\title{
Leading the Construction of Economics and Management Laboratory in Colleges and Universities with the Concept of Green Development
}

\author{
Yun $\mathrm{Li}^{1, \mathrm{a}}$ \\ ${ }^{1}$ Practice Teaching Management Division, Tongling University, Tongling, Anhui,244061, China
}

\begin{abstract}
Green development is the trend of the times. As an important carrier of practical teaching, economic and management laboratories in Colleges and universities should firmly establish the awareness of green development in laboratory construction, and put "green" into all aspects of laboratory construction. This paper discusses the problems of environmental pollution, equipment aging, low resource utilization rate, lack of awareness of green development and complex equipment maintenance in the construction of economics and management laboratories in colleges and universities, and discusses how to implement the green development strategy in the construction of economics and management laboratories, hoping to provide valuable reference for relevant personnel.
\end{abstract}

\section{Introduction}

The report of the 19th National Congress of the Communist Party of China clearly pointed out that we should speed up the reform of the ecological civilization system and build a beautiful China. One of the requirements is to promote green development and carry out actions such as creating energy-saving organs, green families, green schools, green communities and green travel. Laboratory is an important place for teaching and scientific research in colleges and universities, which plays a vital role in the development of colleges and universities. Therefore, how to make the university laboratory on a sustainable and green development road is particularly important[1].

\section{Analysis on the current situation of economics and management laboratories in Colleges and Universities}

\subsection{The hygienic environment of the laboratory is not up to the standard}

Most of the laboratories in colleges and universities in our country have good environment, but there are also some laboratories that do not meet the standard of hygienic environment. Especially in the economic and management laboratory, the tables and chairs of the economic and management laboratory are densely placed, the number of computers is large, and there are many health dead ends. Some of the earlier built laboratories used wooden tables and chairs, whose legs and legs had been corrupted. There are even some laboratories with lower floors, because of humidity and lack of sunshine all the year round, the walls, tables and chairs are moldy and hairy, and bacteria breed, which seriously affects the environmental sanitation of the laboratory.

\subsection{Lack of attention in laboratory construction}

In the traditional view of most people, economics and management majors don't need to rely on laboratories for teaching like science and engineering majors, which leads to many restrictions in the construction process of economics and management laboratories, such as insufficient project demonstration, insufficient funds and poor equipment. Therefore, teachers and students often encounter some difficulties in the use of software and hardware in the process of practical teaching, such as hardware devices can't keep up with the update speed of software, some software can only be used in the limited hardware environment or operating system, and hardware equipment aging and slow running. These problems not only greatly affect the teaching effect of teachers, but also suppress the enthusiasm of students[2].

\subsection{Lack of awareness of green development}

In some people's view, to practice the concept of green development, we only need to do a good job in environmental protection in the process of construction and use of engineering laboratories, while ignoring the construction and use of economic and management laboratories also need the guidance of the concept of green development. For example, in the process of laboratory

aemail:1211@tlu.edu.cn 
construction, there may be some problems, such as lack of funds or inadequate supervision, resulting in the decoration materials are not environmentally friendly and the decoration process is shoddy. In addition, in the process of using the laboratory, the flow of people is large, some students do not pay much attention to environmental health, and they discard the experimental waste and domestic waste at will, so they have a weak sense of green environment. There are a large number of economic and management laboratories, and the arrangement of experimental courses is intensive. Relying on only a few laboratory managers is bound to be unable to supervise the corner of the laboratory, which requires all the teachers and students who enter the laboratory to firmly establish the awareness of green development, and work together to create a green laboratory.

\subsection{The utilization rate of some laboratories is low}

There are a large number of economic and management laboratories in Colleges and universities to meet the needs of experimental courses for all economic and management majors. Among these laboratories, there are two types of laboratories with relatively low utilization rate, one is those with relatively long construction time, and the other is those with poor ventilation and lighting on the first floor. Compared with the new laboratory, the old laboratory equipment is aging and running slowly. Except for some specific experimental courses which need to use the laboratory supporting experimental teaching aids, other experimental courses can't be carried out in this kind of laboratory, and the utilization rate is very low. However, for the laboratories with poor ventilation and lighting on the first floor, due to the humid air and high failure rate of electronic equipment, the number of computers that can be used normally can't reach the number of class users, so the laboratories need to be replaced, which also reduces the utilization rate of such laboratories. In addition, most of the economic and management laboratories in colleges and universities are only open to the experimental courses of their own majors, with the main purpose of completing the experimental teaching tasks. However, they are rarely open to teachers and students in their spare time, and the laboratory resources are not fully utilized.

2.5 The number of computers in economic and management laboratories is huge and the maintenance is complex

Most of the traditional economic and management laboratories are based on computers of various brands and models. All the software and hardware are bound to the computer, and each computer has a relatively independent operating system. Although the degree of freedom is high, as long as any component has problems, the system may not work normally. Taking the university where the author works as an example, the total number of computers in the economic and management laboratory is more than 1500 , and the task of the experimental course is heavy, and the flow of people is large. The laboratory managers spend a lot of time to deal with various computer failures every day, which not only wastes manpower, but also affects the normal progress of experimental teaching. In addition, the update speed of the computer can never catch up with the update speed of the teaching simulation software. After the software is updated, the requirements for the configuration of the computer are higher. Often, the old computer cannot meet the performance requirements of the new software, and has to be idle or eliminated. If the machine is replaced year by year, it is bound to be a large cost[3].

\section{The green development road of the construction of economics and management laboratory in Colleges and Universities}

\subsection{Strengthen the comprehensive management of Laboratory environmental sanitation and build an effective green environment evaluation system}

The laboratory green environment evaluation system can provide theoretical basis and reference standards for the construction of laboratory green environment, which should cover the laboratory space layout, equipment and instruments, health status, safety management, air quality and other evaluation indicators. In each evaluation index, the corresponding evaluation level should be established. The laboratory management personnel should score regularly according to the level, and the unqualified laboratories should be rectified within a time limit. Those who are still unqualified should be held responsible, so as to promote the construction and development of the laboratory green environment[4].

\subsection{Change the concept and improve the importance of economic and management laboratory construction}

Colleges and universities need to change the traditional concept, fundamentally realize the important role of practical teaching in the teaching of economics and management specialty, attach importance to the construction of economics and management specialty laboratory, and provide the necessary human, financial and material resources for the laboratory construction. Economic and management laboratories are different from science and engineering laboratories. There are strong correlations and commonalities among various specialties of economic and management. Therefore, in the initial stage of laboratory construction, we should fully consider this characteristic, repeatedly investigate and demonstrate, and carry out laboratory construction on the basis of reasonable laboratory layout and optimal resource allocation, so as to avoid duplication and waste of resources. 


\subsection{Firmly establish the awareness of green development and put green culture into all aspects of laboratory construction}

Teachers and students of the whole school should firmly establish the awareness of green development, strictly control the construction process of the laboratory, and prohibit the decoration materials that are not up to the environmental protection level from entering the laboratory. In the allocation of laboratory resources should also be layer upon layer screening, to ensure that the allocation of laboratory resources is reasonable and can serve the practical teaching to the maximum extent. While teaching professional knowledge, experimental instructors should also stand on the strategic height of green development, standardize their words and deeds with a strong sense of responsibility, cultivate students' professional skills, and cultivate students' good experimental habits, so as to achieve efficient experiment, civilized experiment and green experiment[5].

\subsection{Improve the utilization rate of economic and management laboratories}

Low utilization of laboratory resources is a waste of resources. The concept of green development requires us to improve the utilization of laboratory resources and put an end to all waste. To improve the utilization rate of laboratory resources, we can start from three aspects: one is to extend the opening hours of teachers and students, such as evenings and weekends, so as to ensure that students and teachers can use the laboratory in time to complete experimental projects; the other is that the open laboratory should not only aim at the inherent economics and management majors, but also be open across majors, colleges and even schools, so as to make the laboratory resources more efficient The third is to strengthen the cooperation between the laboratory and government agencies, social enterprises and scientific research institutions, so as to realize the complementary advantages of resources, improve the utilization rate of laboratory resources and enhance the social influence and contribution of the laboratory[6].

\subsection{Building green economy and management laboratory with cloud desktop system}

In view of the large number of university laboratory computers and complex maintenance problems, the construction of cloud desktop system can be said to be the most reasonable solution. First of all, the construction of cloud desktop system means lower purchase cost. Taking a laboratory with 80 people as an example, it generally needs 5 high-performance servers and 80 terminal displays. The comparison with traditional laboratories in terms of purchase is shown in Table 1:

Table 1. Comparison of purchase cost between cloud desktop system laboratory and traditional laboratory

\begin{tabular}{lcclllll}
\hline \multicolumn{3}{c}{ Cloud Desktop System Lab } & & \multicolumn{3}{c}{ Traditional laboratory } \\
\hline $\begin{array}{l}\text { Equipment } \\
\text { name }\end{array}$ & Unit Price & number & $\begin{array}{l}\text { amount } \\
\text { money }\end{array}$ & $\begin{array}{l}\text { Equipment } \\
\text { name }\end{array}$ & Unit Price & number & $\begin{array}{l}\text { amount of } \\
\text { money }\end{array}$ \\
$\begin{array}{l}\text { The server } \\
\begin{array}{l}\text { Terminal } \\
\text { display }\end{array}\end{array}$ & 25000 & 5 & 125000 & computer & 3500 & 80 & 280000 \\
\hline
\end{tabular}

It can be seen that the cost of building a new cloud desktop system laboratory is about $26 \%$ less than that of the transmission laboratory. Moreover, the terminal computer does not undertake the operation of the program. In the actual laboratory construction, we can even use the computer equipment that has been eliminated. In this way, the cost can be saved by about $55 \%$, which not only makes full use of the existing resources, but also greatly saves the purchase cost. Second, the maintenance of equipment is more simplified. The terminal is just a simple input and output device, which does not carry out complex calculation and program operation, and does not need software installation and upgrade. It has longer service life and simpler maintenance work. Third, higher performance experience. The cloud uses ultra-high performance host devices. Teachers and students can use the desktop environment deployed in the cloud terminal on the terminal devices, and their experience is completely consistent with that of high-performance computers[7].

\section{Conclusion}

With the rapid development of science and technology, the problem of environmental pollution is becoming more and more serious. How to do a good job in the construction of university economic and management laboratory under the premise of environmental protection is an urgent problem to be solved. Adhere to the concept of green development, from improving the utilization rate of laboratory resources, enhancing the environmental protection awareness of teachers and students, introducing advanced cloud platform technology and other aspects, continue to explore new ways of laboratory construction, in order to improve the management level of the laboratory, and make greater contributions to the construction of a beautiful and harmonious green campus[8]. 


\section{Reference:}

1. Chen C.(2018) The Construction of Green Electronic Information Laboratory in University.Journal of Hefei University, 2:108-112.

2. Hong P.P.(2020) Exploration and Reflection on Laboratory Construction of Management Liberal Arts in the New Era. Journal of Green Science and Technology,19: 219-222.

3. Sun Y.L.,Huang M.H.(2017) Exploration on construction of cloud desktop of liberal arts experimental demonstration teaching center in colleges and universities.Experimental Technology and Management,5:212-214.

4. Guo B.S.,Yuan F.G.,Ding B.(2015) Evaluation System of Green Environment in University Laboratory. Building Energy Efficiency,7:98-99.

5. He P.P.,Wang B.N.,Gong S.W.et al.(2017) Leading construction and development of university laboratory by five major development concepts. Experimental Technology and Management,7:1-3.

6. Zhang J.J.,Li L.Z.,Wang F.Q.et al.(2019) On Practice of Constructing The Innovation Mode of Open Laboratory in Local Universities. Journal of Southwest China Normal University,7:150-155.

7. Zhang H. (2012)Cloud Computing Technology and Its Application in Building a Green Computer Laboratories in Universities .Value Engineering, $11: 180-181$.

8. Li M.H.,Gao X.J.,Mao Y.et al. (2013)Talking about building green laboratory of university. Laboratory Science, 2: 197-199. 